\title{
WASTE MANAGEMENT USING LEAN CONSTRUCTION AND BUILDING INFRMOATION MODELLING: SYSTEMATIC LITERATURE REVIEW
}

\author{
Mahmoud Karaz ${ }^{(1)}$, José Cardoso Teixeira ${ }^{(1)}$ \\ (1) Department of Civil Engineering, University of Minho, Guimarães, Portugal
}

\begin{abstract}
Construction waste chains are propagated into interrelated, fuzzy, and complex nature, which make them challenging to address. The conventional approaches have failed in treating construction waste because they focus on waste symptoms instead of diagnosis the root causes. Additionally, there are few attempts to capture the whole taxonomies of waste based on the theory of production in construction. The synergies of Lean and BIM are well-documented improvements to construction production theory and practices and constituted the foundations to provide productivity improvements, automated workflows, and sustainable development. Lean-BIM facilitates significant analytical and actionable measures towards construction waste, by attacking waste at source, and limiting its' occurrence. However, many measures to address waste elimination are not explored collectively. Thus, this paper reviews the impact of Lean and BIM synergies on waste taxonomies and elimination methods. Four main areas of knowledge communicated over the period 2000-2019, production planning and control systems; design management; supply chain management; and pursuits towards sustainable lean construction. Based on a systematic review of 32 published papers in academic journals and conference proceedings. There is a great need to provide more evidence-based research that reports lean metrics and BIM workflows impacts on core construction wastes. Research insights and future developments towards waste elimination identified and suggested, not only from a production point of view but also sustainable dimensions.
\end{abstract}

\section{Introduction}

Waste indicates significant inefficiencies in production systems in general and in construction projects in particular. The identification and elimination of waste would trigger intrinsic and instrumental actions to improve both productivity and sustainable performance of construction projects. Indeed, waste exists inside and outside production systems. Inner production waste is significant and commonly associated to as Non-Value-Added works (NVA) which is the utilisation of time, space, resources, material, and information without adding value to internal 
or external customers [1], [2]. Additionally, production waste may be reshaped in other forms of waste, represented in functional failures coupled with environmental, safety, and cost issues. Globally, NVA constitutes $49.6 \%$ of construction activities, as reported in a metanalysis between (1970-2000) [3]. A Swedish study has shown that NVA constitutes $17.5 \%$ of labour time. At the same time, BIM designers spend $70 \%$ of their time on reviews and $13 \%$ on design rework [4]. Moreover, the EU construction industry produces enormous amounts of construction and demolition waste (CDW), with more than 800 million tons yearly of [5]. In addition to enormous environmental issues related to greenhouse gases (GHG), landfills, wastewater and accidents or fatal injuries [6], [7]. The existence of waste within or outside production systems typically influences cost excess and other financial issues if not well managed or treated.

Another reason for a large amount of waste in the industry is caused by the belated recognition of waste elimination as a critical construction management function. Koskela et al., 2012 explored the history of waste. They explained that the concept of waste was abstracted away from classical management, economic, organisational, operation management theories until its' re-emergence by Toyota Production Systems (TPS) in the second half of the 19th century [8]. Despite this growth through lean principles diffusion, there is no profound theory that captures the concept of waste and maps it to another context than manufacturing [9]. Additionally, the well-known list of Ohno was transposed into construction context without reflection to construction management theories and construction peculiarities (such as one-kind-production, temporary organisations and site production), which makes Ohno's list defective within the construction context [10]. Actually, this taxonomy of waste was not fully justified because of the significant interrelationships between construction production and design, unlike manufacturing [11].

In the view of above, a proper taxonomy of construction waste is necessary to reflect the viewpoints of Transformation Flow Value (TFV) theory which respond to peculiarities of construction [11]. Figure 1 captures the chain of wastes within production systems and illustrates the output of a construction production system; Figure 1 also counted a broad conception of construction waste that mapped to TFV. Based on a recent review by Formoso et al. 2020 [2], some terminologies such as Making-Do, WIP, Unfinished works and Task diminishments have rarely been used or interpreted in research and practice. That requires appropriate lean construction approach that portrays its main philosophy "managing with scarcity", therefore providing an in-depth understanding of waste and utilising the required technology to achieve waste elimination as a significant step for overall improvement.

The consensus shows that BIM is the leading technology and information system to support the lean construction journey, by imposing measures to facilitate waste reduction practices such as elimination variability and lead time [13], [14]. The evidence shows that lean principles can tackle waste root-causes at strategic and operational levels, through collaboration, learning by seeing and eliminating waste, transparency, decentralised decision-making, continuous improvement and standardisation, which can upscale people knowledge and skills in engaging them towards waste elimination [15]. At the same time, the collaborative workflows of BIM achieve waste elimination by resolving conflicts and errors in system design to hurdle the fragmented nature of construction information systems and technologies. However, the current theoretical and empirical research has rarely captured Lean-BIM interactions and related them to full taxonomy of construction waste; even a systematic review approach is lacking to address waste elimination collectively [2]. That has been caused by the inherited traditional view of 
production, which is still rooted in the current practice of construction management, even in some applications of Lean-BIM. This paper aims to systematically explore the impact of Lean and BIM on waste taxonomies and elimination methods. This research comprises of three sections: the first explains and justifies the method of research, while the second and the third facilitate descriptive and content analysis for the literature review outcomes. Finally, the conclusion remarks associated with research gaps and future insights are drawn.

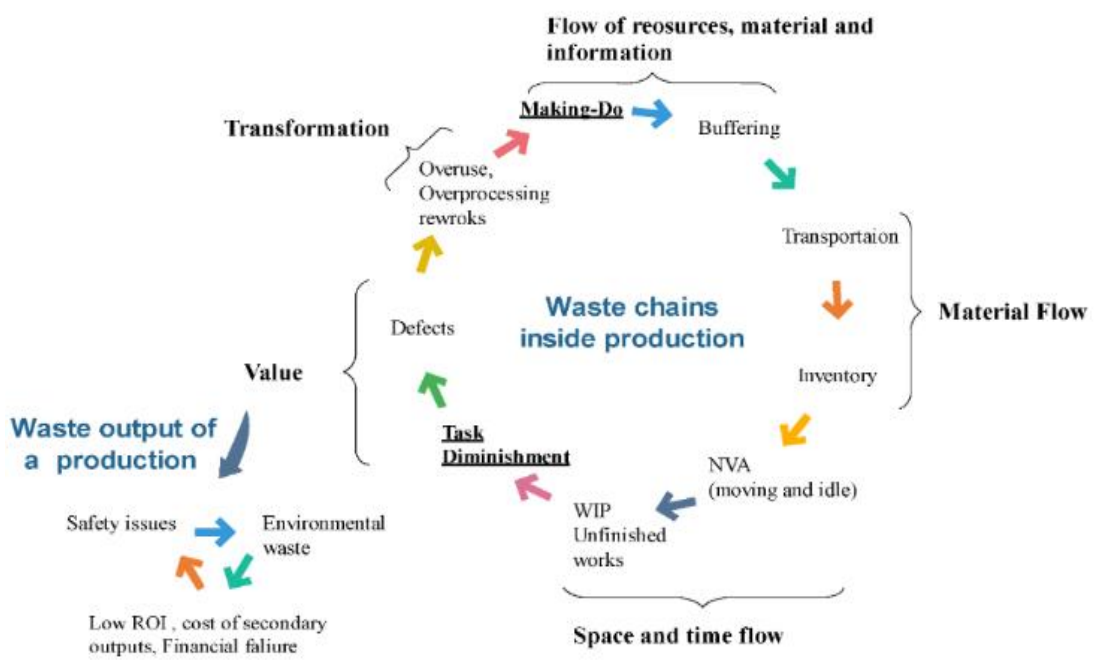

Figure 1: Chain of construction waste, based on TFV theory [12] and taxonomies adapted from [2].

\section{Methodology}

The Systematic Literature Review (SLR) has been employed to enhance the knowledge on the integration of Lean Construction and BIM functionalities for waste elimination. SLR is defined as a pre-planned methodology framework to identify, select, appraise and summarize the results from distinct literature sources on a similar scope [16]. SLR is currently used to inform academics, professionals organisations, and policymakers on the concluded evidence on some issue. Accordingly, SLR has been selected to reach more evidence-based results on waste by learning from empirical reports on Lean-BIM synergies. The SLR retrieved records from [Engineering Village, Web of Knowledge, and Scopus] by searching ["Lean Construction" AND "BIM" OR "Building Information Model*" AND "Waste"] in Abstract, Keywords and Titles criteria. The primary criteria were to include studies using the integration of Lean and BIM to eliminate various forms of construction waste. Other constraint applied to the selected journal papers and compelling conference proceedings, has been to only include records in English and conducted between 2000 to 2019. Based on the methodology illustrated in Figure 1, the number of included records has been (32) documents. Any published paper that would not hold analysis on the three topics collectively "Lean construction", "BIM" and "Waste" was excluded in order to provide more concise results in the analysis. Because of lacking research on the use of Lean-BIM in waste management retrieved from the abovementioned databases, a 
considerable number of snowballed documents have been added to the funnel of the literature review, as shown in Figure 2.

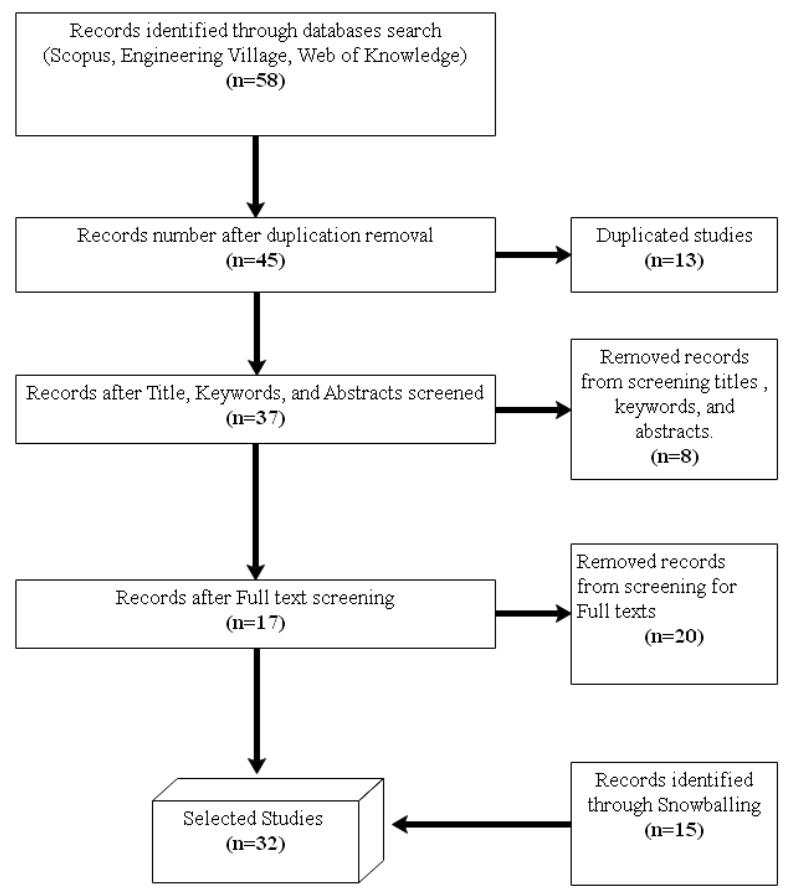

Figure 2: Screening and appraisal stages for Literature review

\section{Descriptive analysis}

The studies included in this review comprise of 32\% production planning and control; $25 \%$ design management; 22\% Supply chain management; $21 \%$ Sustainability. They also use different definitions for waste, regarding measures, and metrics into various contexts of construction which makes studying them systematically more challenging [2], despite the consensus on the significant interdependence between production waste and other wastes (environmental, capital, and safety issues) [6], [17]-[19]. There is still little attention to measuring their effect collectively, and it lacks formalised methods to analysis wastes such as Making-Do, Task-diminishment, unfinished works, and other predetermined production waste.

\section{Content analysis}

Lean project management can manage the hand-offs across overall interfaces of construction management and the construction value chain, namely, among manufacturing, design, supply chain, construction, Operation and Maintenance (O\&M) until end of life stages (EoL) [20], [21],[22]. Among other things, planning and control methods that allow practitioners to perform work structuring and facilitate pull and one-piece flow, considering the interdependence between design and construction interfaces. LC design helps to coordinate and eliminate tasks 
the negative iterations of design tasks, besides LC methods and techniques to reduce lead times in supply chain management (SCM) for offsite and on-site production [26]. Similarly, the capabilities of BIM functionalities assist in flowing down the design intent across the project and building life-cycle and hold capabilities to facilitate consistent design for process and product, which provide better productivity and sustainability performance with long-term value determination [23]-[25]. The in-depth thematic analysis exposed four knowledge area inter alia: (i) design management; (ii) production control systems; (iii) supply chain management; and (iv) sustainability. The following sections analyse the effectiveness of current methods in each area on production waste, across design, supply chain, and construction.

\subsection{Design management}

Although the positive interactions of BIM in achieving lean principles, there are negative synergies, that is generating rapid information which leads to an increased the number of unfinished works, work in progress (WIP), batch size (BS) which are wastes in lean paradigm [14]. Negative design cycles are waste in BIM process, caused by communication, technological, and competency problems [26], and the significant symptoms of design waste can be represented in: high number requests for information (RFI), change orders, and reworks. Due to lack of clarity in client requirements, tight time frames and uncertain conditions for production system and supply chain, which mainly associated to low levels in collaboration and coordination between project parties [4]. That leads to pushing the designers to commit more NVA activities such as inspection, waiting, and reworks. While the exchange of information (IE) is not standardised in the construction design because of one-of-kind production characteristic [27], causes fragmented information flow and workflows within design cycles. The root cause of this problem is rooted in the transformation view (traditional management), which leads to perceive BIM as a design tool rather than a process to deliver the design intent. Therefore, practitioners focus on local optimisation rather than integrative and collaborative coordination that aims at overall improvement for the project and involved organisations. Since BIM and Lean harmonise interchangeably to improve total construction practice, BIM process can be performed and controlled based on the TFV theory, that diffuse production theories into construction design practice, and using their indicator into construction design context [13], [27]. The following subsection discusses the effectiveness of Production waste indicators to improve the BIM process and operations management.

\subsubsection{Waste Indicators of BIM design management}

BIM design management aims at coordination of the process of information production and processing through measuring three significant elements, information flow, information exchange, and social interactions to produce and process design intent. Previous research shows that Lean principles and BIM functionalities are interacting not only for plan and control construction production but also for design management [13], [25], [28]. There is a consensus on Lean metrics in measuring BIM designer's productivity and related quality of design, and by determining waste, indicators are more effective measures to initiate actions for instrumental and intrinsic improvements.

Dubler et al. (2011), identified wastes in BIM schematic design IE, after mapping it into Ohno's list during the phase, several suggestions were drawn such as LOD to reduce overproduction, centralising models, design validation to reduce errors and omissions [29]. An Israeli study conducted by Tribelsky and Sacks (2010) on IE in design detailing phase for 58 subprojects, 
they simulated and visualised information flow by using production indicators based on factory physics; comprised bottlenecks (BN), Batch Size (BS), Cycle Time (CT) and WIP. Which shown that design reworks, changes, errors, and omissions are dependent on the bottleneck, WIP, and velocity of development [30]. However, the propagation of waste not highlighted and measuring the impact of the team's interactions across the design processes was missed.

Al Hattab and Hamzeh have studied the impact of BIM to achieve lean enhancements on design information flow during schematic and conceptual phases of the design stage; they combined approaches from social mechanisms and process dynamics. By utilising Agent-BasedModelling (ABM) and Social Network Analysis (SNA) to visualise the trends and metrics of information flow that consisted of queuing time (QT), WIP, BS, BN, as well as helped to understand the interactions between design teams (collaboration). This study contended that focusing on technical capabilities and collaborative skills, are necessary to diminish the negative iterations in design and to facilitate smooth workflows to convey the value between disciplines and end-users [4], [31].

Table 1 collects the metrics of lean construction used to control and eliminate waste in the BIM process. The adoption of lean construction manages BIM design process is challenging, because of the high level of variability and uncertainty, especially in earlier design phases. Moreover, the published efforts failed to capture core wastes such as making-do, task-diminishment, and unfinished works and their impact on the BIM process. Most of the literature reflected on taxonomies of waste based on Ohno's list, which is not entirely justified in the construction context [11], more formalised methods for BIM design management based on TFV perspectives should be done [32], with attention to construction design context and its' trade-off with other interfaces.

Table 1: Lean metrics in controlling wastes in the BIM process

\begin{tabular}{llrrrrrr}
\hline Reference & Location & QT & WIP & BS & BN & V & CT \\
\hline Dubler et al. 2010 & USA & & $\sqrt{ }$ & $\sqrt{ }$ & & & \\
Tribelsky and Sacks 2010 & Israel & & $\sqrt{ }$ & $\sqrt{ }$ & $\sqrt{ }$ & $\sqrt{ }$ & $\sqrt{ }$ \\
Al Hattab and Hamzeh 2018 & Lebanon & $\sqrt{ }$ & $\sqrt{ }$ & $\sqrt{ }$ & $\sqrt{ }$ & & $\sqrt{ }$ \\
\hline
\end{tabular}

Where QT: Queuing time; WIP: Work in Progress; BS: Batch time; BN: Bottlenecks.

V: Velocity of development; CT: Cycle Time

\subsubsection{Lean design management methods and techniques}

Several studies called for more BIM management methods that control information flow and to facilitate usability and accessibility. The process of design validation, facilitate operable handoff to reduce significant root causes of IE and information flow waste [29]. The design validation process is also an improvement window for learning curve in organisations without fragmented knowledge between or within projects. Similarly, the Root causes analysis (RCA) facilitates a common language for wastes and determines the right tools to assess and eliminate waste [33]. LC offers diagnosis techniques such as value-steam mapping VSM, RCA, and process mapping, those techniques to be diffused into BIM workflow management to improve the learning curve, with exploring the root causes of inefficient BIM implementation and coordination, that build continuous improvement culture and enable faster reactions towards 
future and similar issues. Thus, integrated design methods help to improve coordination, collaboration, and communication of design intent, moreover, facilitate informed decisionmaking process by sharing awareness regarding waste elimination. However, there is no clear guidance that assists stakeholders to select appropriate approaches of Lean and BIM to achieve their waste elimination goals. More research should be carried out on measuring the impact of each Lean-BIM interactions on design process management, to eliminate not only wastes during design and production but also extended types of waste across the building life cycle.

\subsection{Production planning and control systems}

Two dominant construction production systems were proposed to the industry since 2010, namely KanBIM and VisiLean [24], [25]. By exploiting the identified Lean-BIM interactions and requirements in the previous paper [13]. Those two systems addressed the fragmentation between production and design and harnessed BIM capabilities in supporting construction practitioners at various organisational levels. KanBIM and VisiLean overcome the deficiencies of the existing BIM software and ERP systems, by supporting pull and push planning and enabling real-time information exchange regarding the process and product statuses. Those systems approved on BIM capabilities in achieving lean principles based on TFV theory. Although the advancement of those systems in reduction of CT, WIP, and Making do, there is no empirical evidence on the reduction rates and their effect on waste chains in construction. Moreover, automated solutions are still missing from KanBIM and VisiLean systems, and information in building models does not provide holistic overview on resources and materials on site. Finally, those systems need more integrations regarding supply information reach full JIT system.

Based on the analysis presented in Erro! A origem da referência não foi encontrada., the current production planning and control systems in the construction industry do not adequately address production wastes. The industry needs a holistic artefact that makes systemic and pointwise change [34], the impact of those artefacts will not only focus on total production waste elimination but also including other predetermined wastes and relate them to value generation, based on the extensions to technology in BIM and theoretical background of TFV. 
Table 2: The effectiveness of production planning and control systems on waste elimination

\begin{tabular}{|c|c|c|c|c|c|c|c|c|c|c|c|c|c|c|}
\hline Model name & 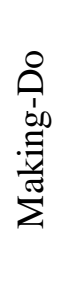 & 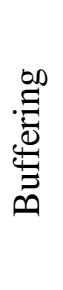 & 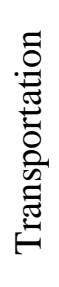 & $\begin{array}{l}\overrightarrow{0} \\
\stackrel{0}{0} \\
\stackrel{0}{0}\end{array}$ & . & 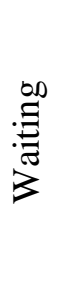 & 3 & 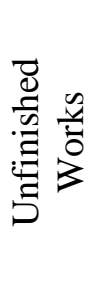 & 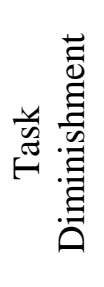 & $\frac{n}{\stackrel{0}{0}}$ & $\begin{array}{l}n \\
\frac{1}{0} \\
0 \\
0 \\
0 \\
0\end{array}$ & 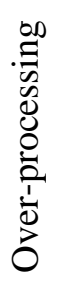 & $\begin{array}{l}0 \\
\overbrace{0}^{0} \\
0 \\
0\end{array}$ & Cite \\
\hline KanBIM & $\mathrm{x}$ & $\mathrm{x}$ & & $\mathrm{x}$ & & $\mathrm{x}$ & $\mathrm{x}$ & $\mathrm{x}$ & $\mathrm{x}$ & $\mathrm{x}$ & $\mathrm{x}$ & & & [24] \\
\hline VisiLean & $\mathrm{x}$ & $\mathrm{x}$ & & $\mathrm{x}$ & & $\mathrm{x}$ & $\mathrm{x}$ & $\mathrm{x}$ & $\mathrm{x}$ & $\mathrm{x}$ & $\mathrm{x}$ & $\mathrm{x}$ & & [25] \\
\hline $\begin{array}{l}\text { Vertically } \\
\text { integrated } \\
\text { scheduling }\end{array}$ & & & $x$ & & $\mathrm{x}$ & $\mathrm{x}$ & & & & $\mathrm{x}$ & $\mathrm{x}$ & $\mathrm{x}$ & $\mathrm{x}$ & [17] \\
\hline $\begin{array}{l}\text { Visual } \\
\text { Production } \\
\text { Management } \\
\text { System }\end{array}$ & & & $\mathrm{x}$ & $\mathrm{x}$ & $\mathrm{x}$ & $\mathrm{x}$ & $\mathrm{x}$ & $\mathrm{x}$ & & $\mathrm{x}$ & $\mathrm{x}$ & $\mathrm{x}$ & $\mathrm{x}$ & [35] \\
\hline $\begin{array}{l}\text { Work team } \\
\text { efficiency } \\
\text { system }\end{array}$ & & & $\mathrm{x}$ & $\mathrm{x}$ & $\mathrm{x}$ & & $\mathrm{x}$ & $\mathrm{x}$ & & & $\mathrm{x}$ & & & [36] \\
\hline $\begin{array}{l}\text { LOB integrated } \\
4 \mathrm{D} \text { planning }\end{array}$ & & $\mathrm{x}$ & & $\mathrm{x}$ & $\mathrm{x}$ & $\mathrm{x}$ & $\mathrm{x}$ & $\mathrm{x}$ & & $\mathrm{x}$ & $\mathrm{x}$ & $\mathrm{x}$ & & [37] \\
\hline $\begin{array}{l}\text { BIM integrated } \\
\text { in-process } \\
\text { quality control }\end{array}$ & $\mathrm{x}$ & $\mathrm{x}$ & & $\mathrm{x}$ & & & $\mathrm{x}$ & $\mathrm{x}$ & & $\mathrm{x}$ & $\mathrm{x}$ & $\mathrm{x}$ & $\mathrm{x}$ & [38] \\
\hline
\end{tabular}

\subsection{Supply Chain Management (SCM)}

SCM in terms of waste reduction aims at compressing cycle times of deliveries and therefore reduce lead times [20]. By seeking for resources harmonisation between production plans, suppliers, and inventories through improvements in Site Layout Planning (SLP), suppliers' relation, and delivery management. SLP comprised of managing material storage, safety space, and transportation frequency. On the other hand, the role of BIM in achieving Lean supply system is to support pull information from production conditions to the supplier, in order to deliver the right material, at the right time according to schedule, in the right place corresponding to SLP, which defines Just-in-Time in SCM. Lean-BIM integrations help to improve process transparency through SLP that assist stakeholders in understanding temporary facilities to provide better allocation on the site [39]. Lean and BIM facilitate strategic, tactical and operational analysis to support SCM decisions, through design for safety, material logistic, utilisation, resources distribution, pathing and routing address [40], [41]. However, there is no commercial BIM software that automates and manage workspace and workflows at the operational level; hence, Pérez et al. suggested to integrate the current $4 \mathrm{D}$ planning to paths for people and traffic, and routing-related concepts [42].

The advantages of pull signals (such as Kanban and Andon signals) to provide SCM with JIT delivery of materials and parts is a substantial step towards resources management, and 
reduction of waste in terms of energy, materials, and facilitating coordinated sites that constitutes fewer safety issues and interruptions between workflow and workspaces. So that future research should focus on more synchronisation between production demand and supply chain; this can be achieved through pulling detailing and prefabrication/assembly of building systems from LPS successive plans [14]. However, SLP for supply chain and construction site should be given more importance during designing and planning for process and product. Because it is the first step toward integrated supply chain and production system.

\subsection{Sustainable Built Environment}

Production waste has a direct impact on environmental waste (GHG emission, material loss and non-renewable energy consumption) [6], [18]. There is significant evidence on the relationships between Lean, BIM and green construction, and the effectiveness of integrating sustainable KPI and measures from BIM workflows associated with Lean metrics hold promising areas of study. The literature in Lean-BIM and sustainability was conducted in three areas 1) CDW management; 2) Eco-Design; 3) Gas emissions reduction. Lean and BIM not only support CDW planning and execution [43] but also extend to circular economy concepts in terms of dealing with material waste [44], by capturing production plans and depicting accurate site conditions. Then, they can facilitate eco-design which focus on End of Life state, material selection and waste minimisation at early stages of design. Therefore, BIM functionalities support to achieve green-lean concepts, that can reduce the negative environmental impacts, including hazardous materials, by increasing recycle and reuse rates, while maintaining lead time and interactions between resources and workflows [19].

However, the literature lacked empirical verification for this hypothesis and ignored the effect of production waste on CDW or achieving a circular economy. Moreover, economic gains more considered in lean change than environmental aspects, which may be caused by contractual or cost aspects, and therefore the future research needs to align cost and value aspects along with environmental measures to achieve the sustainable state of Lean-BIM propositions[18], [45]. The evidence from both theoretical and empirical research on Green-Lean and BIM highlighted the opportunities to provide holistic waste reduction systems including production waste (CT, LT, variability, defect, and reworks); Environmental waste (material, wastewater and gas emissions); social (accidents, injuries and better work environment) in addition to economic factors related to capital waste.

\section{Concluding Remarks and future research recommendations}

This systematic review was conducted to explore holistic waste elimination across various construction management functions. The contributions of current research and development in BIM and Lean have triggered better understanding and conceptualisation for waste and value generation. Lean construction is a valid paradigm that explains waste phenomena by presenting the context-specific and generic waste actionable taxonomies. Nevertheless, the concept of waste still needs more attention and interwinds with value proposition should be considered. The stream of research focused on single events of construction waste phenomenon; this has led to variety in waste measures, and definitions, which hinders holistic waste elimination approaches [2]. Additionally, Ohno's list is partially compatible with the construction context; in turn, this research suggested more investigation construction-specific waste that captures 
various interfaces of construction management. Moreover, there is no evidence on the breadth and width of understanding for construction waste among lean and BIM adopters, which makes practitioners give less attention to waste control and elimination.

Some arguments were raised on the negative impact of misunderstanding lean messages on workers behaviour, and environmental impacts, namely, safety issues caused by aiming at faster productivity, and the issue of frequent trips in JIT can lead to more gas emission and energy consumption [6], [45]. Thus, more socio-technical research should be carried out to address situational awareness lean messages regarding waste elimination, that is based on the lean philosophy of Respect People.

Lean and BIM development is interdependent, and their innovation level is disruptive but should be taken with small incremental steps [13], [14]. By developing user interfaces that integrate BIM 4D visualisation and simulation with LPS and based on TFV theory [24]. Nevertheless, it is still restricted to production planning and control in the construction stage to reduce the impact of variability and uncertainties. Besides the advancements on integrating production information systems, several gaps are identified. First, lack of automated pull signals for task inputs, hinders JIT effectiveness, because of the variations of the manual inputs and lack of precision from the monitoring remote sensing. Second, the concept of waste was limited for production waste, without considering site layout planning, safety issues, and environmental waste caused by the production system. Third, training or coaching for LPS and completeness of LPS information is critical for successful Lean and BIM, because without addressing sociotechnical factors, the effectiveness of Lean-BIM systems is hindered. Fourth, the design stage effect on waste generation in various forms, and there are few attempts to reducing waste from lean design construction, should be diffused to new taxonomies for waste in the design should be reviewed. Fifth, there is a little evidence on lean construction effect on the whole building life cycle, deconstruction; renovation, and it is still in infancy, which requires more attention for future research.

\section{References}

[1] J. Womack and D. Jones, Lean Thinking-Banish Waste and Create Wealth in Your Corporation. New York: Simon and Schuster, 2003.

[2] C. T. Formoso, T. Bølviken, and D. D. Viana, 'Understanding waste in construction', in Lean Construction Core Concepts and New Frontiers, P. Tzortzopoulos, M. Kagioglou, and L. Koskela, Eds. Routledge, 2020, pp. 129-145.

[3] M. J. Horman and R. Kenley, 'Quantifying Levels of Wasted Time in Construction with Meta-Analysis', Journal of Construction Engineering and Management, vol. 131, no. 1, pp. 52-61, Jan. 2005, doi: 10.1061/(ASCE)0733-9364(2005)131:1(52).

[4] M. Al Hattab and F. Hamzeh, 'Simulating the dynamics of social agents and information flows in BIM-based design', Automation in Construction, vol. 92, pp. 1-22, Aug. 2018, doi: 10.1016/j.autcon.2018.03.024.

[5] Eurostat, 'Recovery rate of construction and demolition waste', Eurostat, the statistical office of the European Union, 2019. https://ec.europa.eu/eurostat/databrowser/view/cei_wm040/default/table?lang=en (accessed Jan. 12, 2019).

[6] S. Ghosh, S. Bhattacharjee, and P. Pishdad-bozorgi, 'A Case Study To Examine 
Environmental Benefits of Lean', Proceedings IGLC-22, vol. 1, no. 405, pp. 133-144, 2014.

[7] CPWR, 'Crane-related deaths in construction and recommendations for their prevention', 2009.

[8] Koskela, R. Sacks, and J. Rooke, 'A brief history of the concept of waste in production', 20th Annual Conference of the International Group for Lean Construction, vol. 44, no. 0, 2012, [Online]. Available: http://usir.salford.ac.uk/23082/.

[9] L. Koskela and G. Ballard, 'Is production outside management?', Building Research and Information, vol. 40, no. 6, pp. 724-737, Dec. 2012, doi: 10.1080/09613218.2012.709373.

[10] R. Vrijhoef and L. Koskela, 'Revisiting the three peculiarities of production in construction', in 13th International Group for Lean Construction Conference: Proceedings, 2005, pp. 19-27, [Online]. Available: http://usir.salford.ac.uk/9377/.

[11] T. Bølviken and L. Koskela, 'Why hasn't waste reduction conquered construction?', in 24th Ann. Conf. of the Int'l. Group for Lean Construction, 2016, no. 2, pp. 1-15, doi: 10.1007/978-3-030-01301-1_1.

[12] L. Koskela, 'An exploration towards a production theory and its application to construction', VTT Technical Research Centre of Finland, 2000.

[13] R. Sacks, L. Koskela, B. A. Dave, and R. Owen, 'Interaction of lean and building information modeling in construction', Journal of Construction Engineering and Management, vol. 136, no. 9, pp. 968-980, 2010, doi: 10.1061/(ASCE)CO.19437862.0000203.

[14] B. Dave and R. Sacks;, 'Construction at the next nexus of Lean and BIM', in Lean Construction: Core Concepts and New Frontiers, Routledge, 2020, pp. 54-84.

[15] Y. Arayici et al., 'Technology adoption in the BIM implementation for lean architectural practice', Automation in Construction, vol. 20, no. 2, pp. 189-195, Mar. 2011, doi: 10.1016/j.autcon.2010.09.016.

[16] J. P. T. Higgins and S. Green, Cochrane handbook for systematic reviews of interventions, vol. 4. John Wiley \& Sons, 2011.

[17] L. Song and D. Liang, 'Lean construction implementation and its implication on sustainability: a contractor's case study', Canadian Journal of Civil Engineering, vol. 38, no. 3, pp. 350-359, 2011, doi: 10.1139/111-005.

[18] I. Nahmens and L. H. Ikuma, 'Effects of Lean Construction on Sustainability of Modular Homebuilding', Journal of Architectural Engineering, vol. 18, no. 2, pp. 155-163, 2012, doi: 10.1061/(ASCE)AE.1943-5568.0000054.

[19] M. Kurdve, J. Hildenbrand, and C. Jönsson, 'Design for green lean building module production - Case study', Procedia Manufacturing, vol. 25, pp. 594-601, 2018, doi: 10.1016/j.promfg.2018.06.096.

[20] G. Ballard and G. A. Howell, 'Lean project management', Building Research and Information, vol. 31, no. 2, pp. 119-133, 2003, doi: 10.1080/09613210301997.

[21]F. Innella, M. Arashpour, and Y. Bai, 'Lean Methodologies and Techniques for Modular Construction: Chronological and Critical Review', Journal of Construction Engineering and Management, vol. 145, no. 12, p. 04019076, Dec. 2019, doi: 10.1061/(ASCE)CO.1943-7862.0001712.

[22] G. Ballard, L. Koskela, G. Howell, and T. Zabelle, 'Production System Design in construction.', In: ANNUAL CONFERENCE OF THE INTERNATIONAL GROUP FOR 
LEAN CONSTRUCTION, 9, no. January 2016, pp. 1-15, 2001.

[23] R. Sacks, C. Eastman, G. Lee, and P. Teicholz, BIM Handbook, Third edit. Hoboken, New Jersey: John Wiley \& Sons, Inc., 2018.

[24] R. Sacks, M. Radosavljevic, and R. Barak, 'Requirements for building information modeling based lean production management systems for construction', Automation in Construction, vol. 19, no. 5, pp. 641-655, 2010, doi: 10.1016/j.autcon.2010.02.010.

[25] B. Dave, 'Developing a Construction Management System Based on Lean Construction and Building Information Modelling', University of Salford., 2013.

[26] M. Tauriainen, P. Marttinen, B. Dave, and L. Koskela, 'The Effects of BIM and Lean Construction on Design Management Practices', Procedia Engineering, vol. 164, no. June, pp. 567-574, 2016, doi: 10.1016/j.proeng.2016.11.659.

[27] E. Tribelsky and R. Sacks, 'Measuring information flow in the detailed design of construction projects', Research in Engineering Design, vol. 21, no. 3, pp. 189-206, Jul. 2010, doi: 10.1007/s00163-009-0084-3.

[28] D. J. Gerber, B. Becerik-Gerber, and A. Kunz, 'Building information modeling and lean construction: Technology, methodology and advances from practice', in Challenging Lean Construction Thinking: What Do We Think and What Do We Know? - 18th Annual Conference of the International Group for Lean Construction, IGLC 18, 2010, pp. 683693.

[29] C. R. Dubler, J. I. Messner, and C. J. Anumba, 'Using Lean Theory To Identify Waste Associated With Information Exchanges On A Building Project Computer Integrated Construction ( CIC ) Research Program, Department of Architec- tural Engineering, The Pennsylvania State University, 104 Engr Unit A, U', ASCE, no. Cic, pp. 708-716, 2010.

[30] E. Tribelsky and R. Sacks, 'The relationship between information flow and project success in multi-disciplinary civil engineering design', in Challenging Lean Construction Thinking: What Do We Think and What Do We Know? - 18th Annual Conference of the International Group for Lean Construction, IGLC 18, 2010, no. July, pp. 140-150.

[31] M. Al Hattab and F. Hamzeh, 'A process-social perspective for understanding design information flow', Lean Construction Journal, vol. 2017, pp. 1-11, 2017.

[32] T. Bølviken, J. Rooke, L. Koskela, T. Bolviken, J. Rooke, and L. Koskela, 'The Wastes of Production in Construction - a TFV Based Taxonomy', in 22nd Annual Conference of the International Group for Lean Construction, 2014, pp. 811-822, doi: 10.1038 /nature14663.

[33] I. D. Tommelein and S. Gholami, 'Root causes of clashes in building information models', in IGLC 2012 - 20th Conference of the International Group for Lean Construction, 2012, vol. 1, no. 510.

[34] L. Koskela, G. Ballard, and G. Howell, 'Achieving Change in Construction', Proceedings of the 11th Annual Conference of the International Group of Lean Construction (IGLC11), 22-24 July 2003, pp. 22-24, 2003.

[35] J. J. Lin and M. Golparvar-Fard, 'Visual Data and Predictive Analytics for Proactive Project Controls on Construction Sites', pp. 412-430, 2018.

[36] X. Zhang, S. Azhar, A. Nadeem, and M. Khalfan, 'Using Building Information Modelling to achieve Lean principles by improving efficiency of work teams', International Journal of Construction Management, vol. 18, no. 4, pp. 293-300, 2018, doi: 10.1080/15623599.2017.1382083.

[37] A. Björnfot and R. Jongeling, 'Application of line-of-balance and 4D CAD for lean 
planning', Construction Innovation, vol. 7, no. 2, pp. 200-211, Apr. 2007, doi: $10.1108 / 14714170710738559$.

[38] J. V. Ibarra, C. T. Formoso, C. Lima, A. Mourão, and A. Saggin, 'Model for Integrated Production and Quality Control: Implementation and Testing Using Commercial Software Applications', in 24th Annual Conference of the International Group for Lean Construction, 2016, pp. 73-82, [Online]. Available: http://www.iglc.net/papers/details/1319.

[39] A. R. Singh and V. S. K. Delhi, "'Site Layout Planning Waste” Typology and Its Handling Through AR-BIM Concept: A Lean Approach', 26th Annual Conference of the International Group for Lean Construction, pp. 123-133, 2018, doi: 10.24928/2018/0475.

[40] J. C. P. Cheng and S. Kumar, 'A BIM-based framework for material logistics planning', in 23rd Annual Conference of the International Group for Lean Construction, 2015, pp. 33-42, [Online]. Available: http://www.iglc.net/papers/details/1158.

[41] Y. L. X. Z. Zhu and F. Zhu;, 'Analysis of Non-Value-Adding Activities in Prefabricated Building Construction Project: Case Study', no. Li 2014, pp. 207-216, 2017.

[42] C. T. Pérez, L. L. A. Fernandes, and D. B. Costa, 'A literature review on 4D BIM for logistics operations and workspace management', in Proc. 24th Ann. Conf. of the Int'l. Group for Lean Construction, 2016, vol. 55, pp. 53-62, [Online]. Available: http://www.scopus.com/inward/record.url?eid=2-s2.057749189056\&partnerID=40\&md5=a0e6b46cda154a6e135ef74c906a2575.

[43] M. Cheng, J.C.P., Won, J., Das, J. C. P. Cheng, J. Won, and M. Das, 'Construction and Demolition Waste Management using BIM technology', in 23rd Ann. Conf. of the Int'l. Group for Lean Construction, 2015, pp. 159-60, [Online]. Available: www.iglc.net.

[44] A. Elmaraghy, H. Voordijk, and M. Marzouk, 'An Exploration of BIM and Lean Interaction in Optimizing Demolition Projects', 26th Annual Conference of the International Group for Lean Construction, pp. 112-122, 2018, doi: 10.24928/2018/0474.

[45] P. Saieg, E. D. Sotelino, D. Nascimento, and R. G. G. Caiado, 'Interactions of Building Information Modeling, Lean and Sustainability on the Architectural, Engineering and Construction industry: A systematic review', Journal of Cleaner Production, vol. 174, pp. 788-806, 2018, doi: 10.1016/j.jclepro.2017.11.030. 